\title{
THE ALIMENTARY LESION IN ANAPHYLACTOID PURPURA
}

\author{
BY
}

\author{
C. L. BALF
}

From the Department of Child Life and Health, University of Edinburgh, and the Royal Hospital for Sick Children, Edinburgh

(Received for Pubucation Fearuary 20, 1950)

Widespread visceral lesions were first described as a complication of cutaneous purpura by Willan in 1808 , but they were not generally appreciated until the publications of Henoch (1874) and
Schönlein (1837) suggested that they constituted a clinical entity. The alimentary changes have been considered comparable to the skin purpura and are frequently referned to as purpura abdominalis.

TARé 1

Clinucal picture of 20 Cases of Anaphylactom Purpura

\begin{tabular}{|c|c|c|c|c|c|c|c|c|}
\hline Case & $\begin{array}{c}\text { Age } \\
\text { (Years) }\end{array}$ & Sex & $\begin{array}{l}\text { Presenting } \\
\text { Signs }\end{array}$ & Colic & $\begin{array}{c}\text { Frank } \\
\text { Medaena }\end{array}$ & $\begin{array}{l}\text { Hacma- } \\
\text { turia }\end{array}$ & Joints & $\begin{array}{l}\text { Other } \\
\text { Complications }\end{array}$ \\
\hline 1 & $5 \frac{1}{2}$ & $\mathbf{M}$. & Colic & + & & + & + & \\
\hline 2 & 4 & F. & Joint pains & & & & + & \\
\hline 3 & 10 & $\mathbf{M}$. & Colic & $++t$ & + & + & & Acute jejunitis \\
\hline 4 & $6 \frac{1}{2}$ & M. & Joint pains & ++ & + & & + & \\
\hline 5 & 2 & M. & Rash, haematuria & + & & + & & . \\
\hline 6 & 11 & $\mathbf{M}$. & Convulsions & + & & & + & Status epilepticus \\
\hline 7 & 101 & M. & Acute myositis & + & + & + & & Severe myositis \\
\hline 8 & 4 & $\mathbf{F}$. & Joint pains & & & & + & \\
\hline 9 & $21 \frac{1}{2}$ & M. & Rash & & & & & \\
\hline 10 & 8 & $\mathbf{M}$. & Joint pains & +++ & + & & & Colic intussusception \\
\hline 11 & 4 & F. & $?$ & + & & & + & \\
\hline 12 & $5 \frac{1}{2}$ & M. & Joint pains & + & & & + & \\
\hline 13 & 78 & M. & Colic & + & & & + & \\
\hline 14 & 10 & $\mathbf{M}$. & Joint pains & + & & , + & & \\
\hline 15 & 9 & F. & Rash & & & & + & \\
\hline 16 & 2 & $\mathbf{M}$. & Rash & + & & + & & \\
\hline 17 & 6 & M. & Colic & ++ & & + & + & Muscle pain \\
\hline 18 & $10 t$ & F. & Rash & ++ & & + & + & Do. \\
\hline 19 & 41 & M. & $?$ & + & + & + & + & Do. \\
\hline 20 & $4 \frac{1}{2}$ & M. & Colic & +++ & & + & & Acute ileitis \\
\hline 20 & & $\left.\left.\begin{array}{r}15 \\
5\end{array}\right\} \begin{array}{c}\mathbf{M} . \\
\mathbf{F} .\end{array}\right\}$ & & 16 & 5 & 10 & 12 & \\
\hline
\end{tabular}




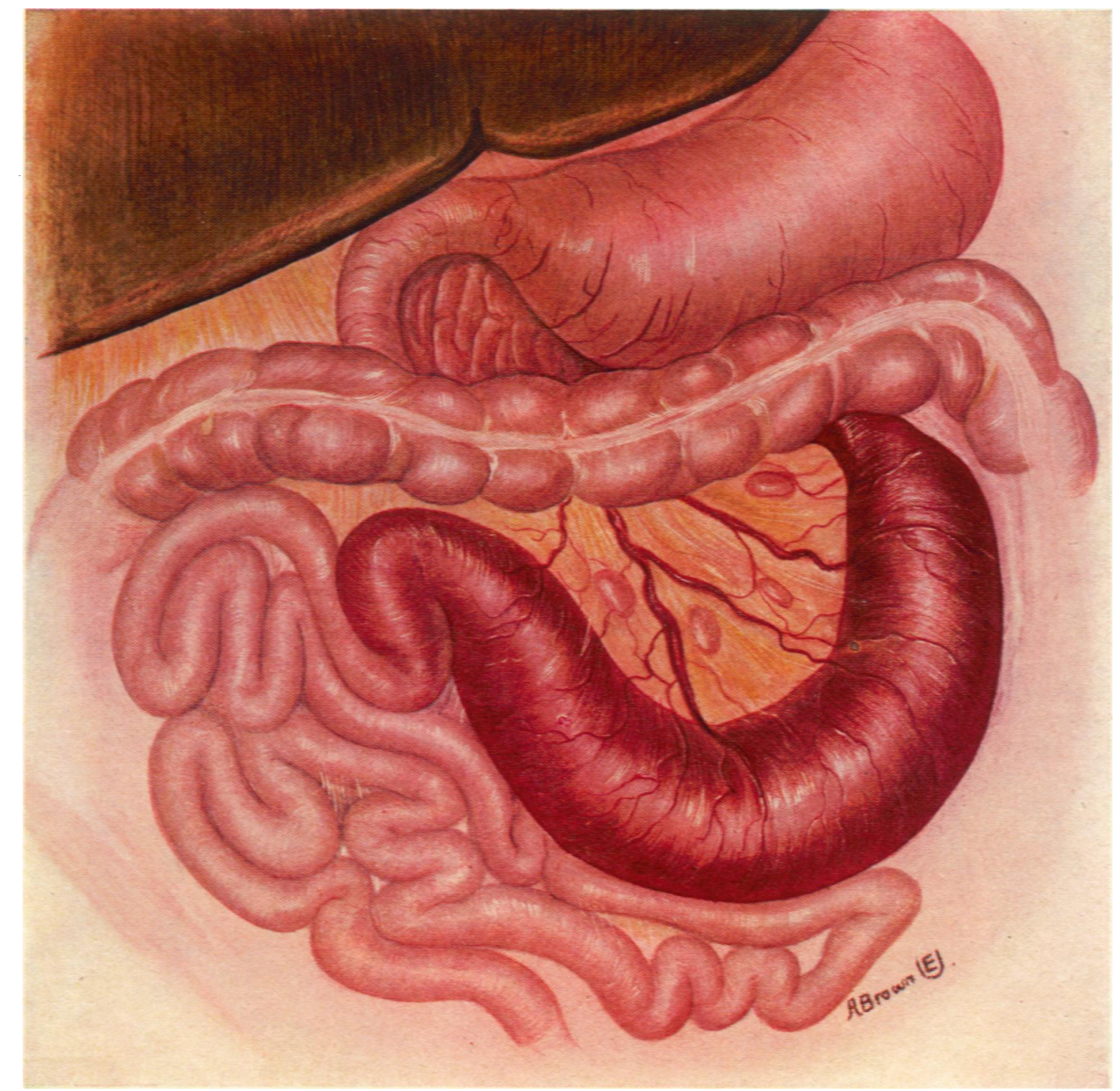

Fig. 1.

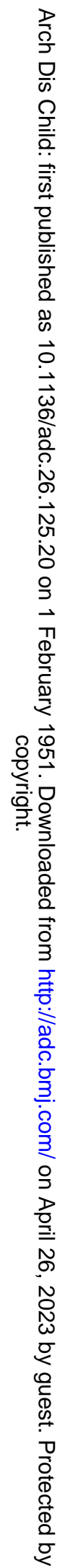


They appear to be of transient importance only, and there is no record of progression to chronic disease of the bowel. On the other hand, the renal lesion in anaphylactoid purpura may become indistinguishable clinically or pathologically from Type I nephritis (Ellis, 1949).

The specificity of the bowel lesion has been questioned (Bailey, 1930), but although it has been thought comparable with that seen in a variety of haemorrhagic diseases, there is little evidence that frank haemorrhage occurs in anaphylactoid purpura. In view of the demonstrable specificity of the skin lesion (Gairdner, 1948), it seems desirable to determine the nature of the intestinal changes.

Final opinion will be impossible until adequate pathological studies have been made of the lesion in the acute phase. This is rarely possible, as operation is not usually indicated unless intussusception or perforation complicates the initial damage. For this reason the following case reports are of value in that they illustrate different stages of the lesion. In four of them the bowel was seen at operation, and in another radiological evidence of abnormal peristalsis was available. The cases were all seen during a period of two years at a children's hospital and were part of a total of 20 cases of anaphylactoid purpura admitted during that period.

Table 1 summarizes the clinical picture in the whole group and permits of ready comparison with previous reports.

As would be expected, the standards of admission to hospital ensure that in all cases widespread and often serious complications were present. This contrasts strikingly with the experience of Davis (1948) who found no important complication in 44 cases. Most of these were seen regularly for several years, so it is possible that the severity of the illness varies largely with the individual and not according to any particular phase of the disease process. Hospital experience in general confirms the present series, and the records of Osler (1914) and Gairdner (1948) may be considered representative.

\section{Case Reports}

Case 1. J.G., a boy, aged 10 years, was admitted to hospital as an abdominal emergency on October 16, 1948. He had been well until eight days earlier when a transient rash appeared on his chest and abdomen. Two days later he had slight diarrhoea which subsided after three days. Colicky pains then started and gradually became more severe. He vomited frequently and retained no fluid.

State on Admission. The patient was an extremely ill child, grossly dehydrated, with early circulatory failure. The abdomen was not distended. There was diffuse tenderness with some slight localization to the left hypochondrium. Bowel sounds were absent. His condition was urgent and, after pre-operative transfusion, laparotomy was performed.

Operation Findings. There was free fluid in the peritoneal cavity. The jejunum was acutely inflamed, bright red, and oedematous (Fig. 1). The segment involved was sharply separated from normal bowel. Obstruction appeared complete and posterior gastrojejunostomy was performed.

POST-OPERATIVE COURSE. The patient improved steadily, though stomatitis was noted seven days after operation. A barium meal a month later showed a functional stoma and he was discharged from hospital.

He was readmitted on January 2, 1949, when he had a purpuric rash which had first appeared a week previously. This was characteristic of the Henoch-Schönlein exanthem, and involved legs, arms and buttocks (Fig. 2a and $2 \mathrm{~b}$ ). He had no pain and looked healthy. Four days later he complained of severe abdominal pain and began to vomit. The vomiting increased and was later

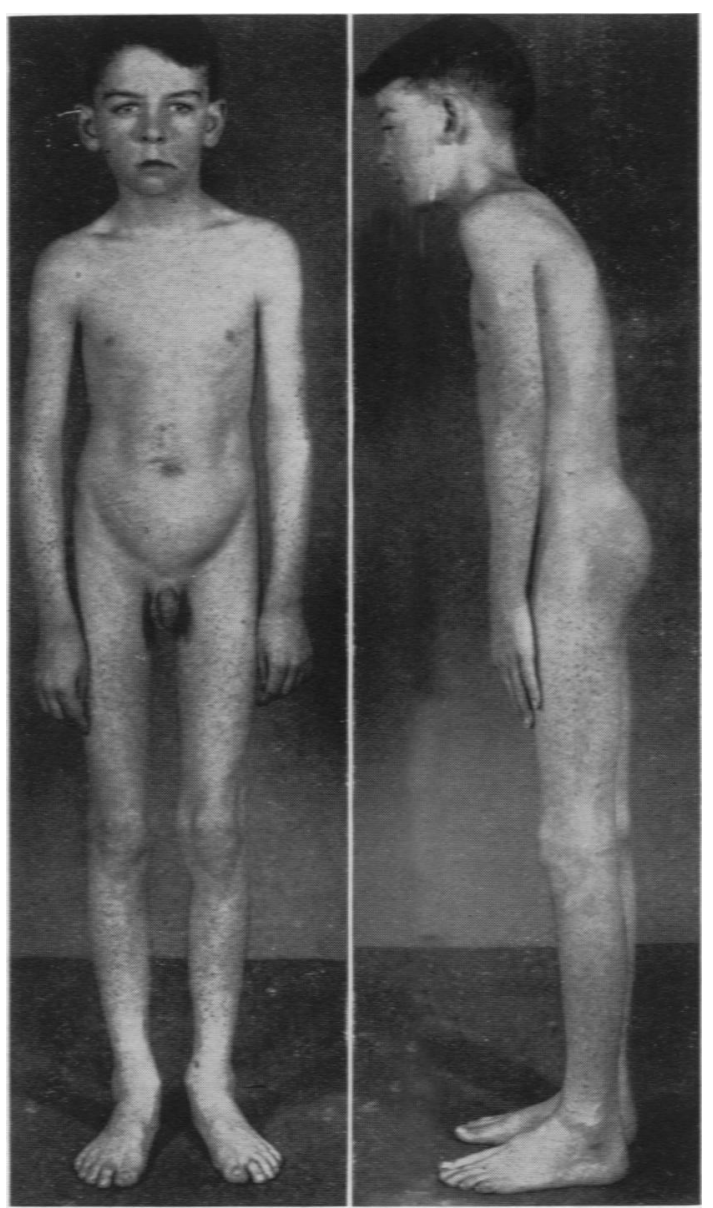

FIG. 2a and 2b.-The typical rash of anaphylactoid purpura. 
blood-stained. The abdomen was diffusely tender and there was increased guarding of the left upper rectus. More purpura appeared and his urine contained numerous red cells. Fluid and ' anthisan,' mg. $\mathbf{3 0 0}$ daily, were given intravenously. Continuous gastric suction was employed and a quantity of mucopus aspirated.

The blood examination findings are summarized in Table 2.

On February 1, a non-herpetic stomatitis appeared, which was similar to that seen previously. The patient had profuse melaena, but his pain diminished and the rash faded. On February 4 a barium meal showed considerable jejunitis, but there was no obstruction. Oral feeding was started and the patient was given anthisan, mg. 500, daily. He continued to improve. Five days later a fresh crop of purpura appeared on feet and hands and after a further two days he again had abdominal pain, which quickly became severe. He vomited forcibly and intravenous fluid was again necessary. The anthisan was stopped, and penicillin, 120,000 units, was given six-hourly. The stomatitis again appeared, but was less pronounced. By February 17 he was again convalescent. On February 21 another crop of purpura appeared and became extensive the next day. One day later (February 23) he had diffuse abdominal pain in the evening and later passed a large quantity of fresh blood per rectum. He vomited once, but did not look ill. Melaena persisted in diminishing quantities for three days. By March 2 he was much improved and was allowed out of bed, but a week later had a slight attack of abdominal pain and two vomits, one of which contained a little blood. No rash appeared until March 14, when a few purpuric spots were noted, but these quickly faded. On March 31, a barium meal still showed some jejunitis. The patient was discharged to a convalescent home, and up to October, 1949, has had no relapse.

The original findings at operation, together with the subsequent demonstration of jejunitis radiologically, make it certain that the abdominal symptoms throughout were caused by acute ' regional enteritis.' It is interesting to speculate whether the changing symptomatology from sudden acute high obstruction to the later colic with melaena represents a different localization of the lesion. The child's condition during the second attack was certainly severe enough to have indicated immediate operation had the diagnosis not been suggested by the previous admission.
No focal sepsis was apparent and no streptococci were isolated from the throat.

The stomatitis was seen altogether on three occasions, although penicillin was given once only. Initially, a possible ciuse was the dehydration and marked sordes, but this could not have applied to later attacks when hydration was adequately controlled throughout. It remains a possibility that the stomatitis was part of the systemic disorder.

Capillary resistance was estimated on several occasions by direct suction using a 1 in. diameter cup for 30 seconds. Petechiae were readily produced in all the stained areas of the skin, indicating some residual capillary damage in these areas. The resistance elsewhere was slightly below normal and, curiously enough, showed no significant alteration when the anthisan was given or when relapses occurred. Parrot (1942) had previously reported a change in capillary resistance when antihistamins were given, but it is probable that the technique was not applied accurately enough in this case to determine any slight difference.

Case 2. H.C., a boy, aged $4 \frac{3}{3}$ years, was admitted on December 23, 1947, with a history of vague ill-health for the previous two months. Two weeks before admission, he had had severe mid-abdominal colicky pain which recurred several times each day and gradually became more severe. His appetite was quite good and his bowels regular until three days before admission when they were constipated. For the last three days he had vomited all food, but had retained a little water. During the last week before admission a number of hard, purple spots had been noted on the buttocks, but no other rash was apparent.

Condmion on Admission. The child was dehydrated and tired, but not acutely toxic. There was tenderness and rigidity in the right iliac fossa. A tender mass was palpable in the same place per rectum, and a diagnosis of appendix abscess was made.

Just before operation some small purpuric spots were noted on the penis, but in view of the definite abdominal findings operation was not delayed.

OPERATION FindINGs. The abdomen was opened through a gridiron incision and a very large quantity of clear fluid escaped. Some coils of small intestine presented at the wound and one coil about 4 in. long and 18 in. proximal to the ileocaecal valve was bright scarlet in colour, but did not appear to be thickened.

TABLE 2

analysis of Blood Investigations in Case 1

\begin{tabular}{|c|c|c|c|c|c|c|}
\hline Date & $\begin{array}{l}\text { Hb. } \\
\text { (\% Sahli) }\end{array}$ & $\begin{array}{l}\text { White Blood } \\
\text { Count }\end{array}$ & Platelets & $\begin{array}{l}\text { Bleeding Time } \\
\text { (minutes) }\end{array}$ & Clotting Time & B.S.R. \\
\hline Jan. 1,1949 & 95 & 9,000 & Abundant & Normal & Normal & 24 \\
\hline Feb. 2, 1949 & & 8,600 & 230,000 & 2 & 3 & 20 \\
\hline Feb. 23, 1949 & 80 & 9,000 & & & & \\
\hline
\end{tabular}

Mar. 12, 1949 
The mesentery of the small intestine proximal to this loop was oedematous. There were a few enlarged mesenteric glands. Appendicectomy was performed and the appendix found to be turgid and thick-walled. When it was opened the mucosa was oedematous and there were several submucous haemorrhages. Histological examination was not performed.

Progress. On December 27 a purpuric rash appeared on the dorsum of both feet extending to about 2 in. above the ankles. A few small spots were noted on the hands. The rash became more widespread next day, but then began to fade. The appearance and distribution were characteristic of anaphylactoid purpura. On the evening of December 29 the child passed two dark stools, giving a strongly positive benzidine reaction. Two days later a further rash appeared, more widespread than before, and slight oedema of the feet was noted. By January 5, 1948, the rash had faded almost completely, but the child complained of severe abdominal pain during the night. Abdominal examination showed no abnormality. On January 6 there was a further outbreak of purpura, now involving the hands, feet, and buttocks extensively.

The temperature remained normal, but the child became gradually weaker and apathetic. He was placed on a milk diet, with the addition of vitamin $\mathrm{C}$, mg. 100 daily, halibut oil, minims 20 daily, and vitamin $B_{1} \mathrm{mg}$. 5, three times a day. The oedema increased.

On January 10 a further rash appeared, now extending to the upper arms and shoulders and up the thighs. There was some colicky pain, but no further melaena. Oedema of the feet disappeared. On January 19 he was given a small transfusion, and following this, there was an increase in the number of red cells in the urine, and for several days he had gross haematuria. He complained of abdominal pain on January 25 and, next day, there was a fresh, profuse outbreak of purpura. As an index of his poor condition, the abdominal wound healed very slowly and there was an excess of unhealed granulation tissue, and later a small incision hernia. By February 17 the child was eating well and taking a good mixed diet. He gained weight during the last few weeks, and when discharged weighed $37 \mathrm{lb}$., a gain of $5 \mathrm{lb}$. since admission.

The child's condition on discharge was good, though there were still a few red cells in the urine. There was, however, little albumen, and for the three weeks before discharge, the urine had shown only slight deviation from normal. No casts were ever seen, and hypertension was absent throughout.

LABORATORY INVESTIGATIONS. Blood counts on Dec. 27, 1947, showed W.B.C., 12,000 c.mm., platelets abundant. Jan. 5, 1948: W.B.C., 8,400 c.mm., platelets abundant. Hess test negative. Clotting time 4 mins. Rleeding time $1 \frac{1}{2}$ mins. Jan. 14, 1948: Hb. $54^{\circ} \%$; W.B.C., 8,000; prothrombin index, $75 \%$ of normal.

URINE. Analysis on Jan. 14 showed numerous R.B.C.s; albumen 2 g./litre. Feb. 15: numerous R.B.C.s; trace of albumen. Mar. 6: occasional R.B.C.s; no albumen. May 5: no albumen. Addis count, 300,000 R.B.C.s in 12 hours.

The Mantoux test on Dec. 27, 1947, was 1/10,000 negative; Feb. 15, 1948, 1/10,000 positive; March 2, $1948,1 / 10,000$ positive.

On Jan. 6 a throat swab showed pneumococci. From Mar. 2 to 5 gastric washings were taken, but no tubercle bacilli were seen.

On Jan. 6 serum proteins were $3 \cdot 54 \%(2 \cdot 5 \%$ albumen: $1 \cdot 04 \%$ globulin); Jan. 14, 4.4\%; Feb. 6, 5.76\%.

The post-operative hypoproteinaemia could not be explained in terms of the patient's previous diet. Vaughan, Thomson, and Dyson (1946) showed that the plasma protein level may fall post-operatively or after severe injury. It has been suggested (Croft and Peters, 1945) that this may be related to the need of particular amino-acids, especially methionine, for tissue repair, which are not readily available from the diet and must be provided by breakdown of tissue protein. In this respect, the unusual granulation tissue and subsequent development of a small incisional hernia are of interest. The oedema of the legs may have resulted from the low plasma proteins, as these were probably not estimated at their lowest level.

The interpretation of the positive Mantoux is difficult. Gairdner (1948) has pointed out that there is an unusual sensitivity to intradermal injection in this condition, and unfortunately no control test was performed. In the absence of collateral evidence of tuberculosis, a final opinion is impossible.

Case 3. J.H., a boy, aged 8 years, was admitted on October 7,1948 . He had complained of earache for three weeks before admission and appeared to be deaf. Similar attacks had occurred in the past and resolved without special treatment. During the last seven days his appetite had been poor and he had vomited several times in the last three days. He was sent home from school three days before admission with a diagnosis of tonsillitis and otitis. On the same day the mother noticed that his face was rather puffy. On the day before admission, the urine was dark red.

CONDInON on ADMission. The patient was a wellgrown boy, drowsy and uncooperative. His temperature was $102^{\circ} \mathrm{F}$., and his skin was pale. He was deaf and there was a purulent discharge from both ears. His face was puffy and there was pitting oedema over the legs and sacrum. A widespread petechial rash was present on the extensor aspect of the limbs. The throat was red, but no pus was seen on the tonsils, which were of normal size. Blood pressure was 14095 . There was gross haematuria and, on microscopy, blood casts were seen.

Progress. He was given penicillin and placed on a fluid diet. No further rash appeared, and the temperature became normal by the fourth day. At this time the blood pressure had fallen to $110 / 75$ and his oedema was decreasing.

By November 5, 1948, he had improved considerably and was alert and cheerful. A short relapse followed a mild respiratory infection on November 19 . Five days later he vomited in the afternoon and some inflammation of the throat was noted. Next day he vomited twice in the morning and later complained of central abdominal pain. His tongue was furred and he had diffuse superficial tenderness of the abdomen. Temperature and 
pulse were normal. In the evening the pain became severe and he was extremely restless, sitting forward and moaning with discomfort. The abdomen was extremely tender and deep palpation was resisted, though there was no rigidity. The tenderness was difficult to localize, but, if anything, was most marked in the right iliac fossa. Rectal examination showed tenderness on the right side. Peritonitis was diagnosed and a laparotomy performed.

Operation Findings. A right gridiron incision was made and a large quantity of blood-stained fluid escaped. The appendix and lower ileum were normal. A right upper paramedian incision was then made and the omentum was found to be lying on the left side. When this was moved several coils of bright scarlet intestine were seen. The area involved extended from the duodeno-jejunal flexure along the jejunum for 16 in. The bowel was grossly oedematous, and of such a brilliant colour that the blood in it must have been nearly fully oxygenated. The duodenum and stomach were normal. It was decided not to perform a short circuit, and the abdomen was closed. An intravenous drip was put up and continuous gastric suction employed.

Post-Operative Course. A course of penicillin was started immediately after operation in a dose of $5,000,000$ units daily. The child was able to take fluids by mouth after five days, and the drip was then stopped.

On the tenth day, after the stitches had been removed, the suture line gave way and a re-suture was necessary. Opportunity was taken to inspect the bowel, which appeared grossly normal.

During the next few days the child occasionally complained of severe colicky pain. It was thought that this might be caused by adhesions. On December 26 he had severe abdominal pain and vomited three times. He was placed on a fluid diet and given an injection of heroin. A radiograph of the abdomen was normal. The pain lasted altogether some $\mathbf{3 6}$ hours, and during this time the haematuria increased until on December 29, 1948 , he passed heavily blood-stained urine. No further purpura was noted. A few days later he seemed well and wanted to get out of bed. The gross haematuria persisted for some three weeks. The B.S.R. remained raised, but because of the child's well-being, it was decided to send him to a convalescent home. While there he contracted chickenpox, which passed uneventfully, and was not associated with any change in the urine.

LABORATORY INVESTIGATIONS. On Oct. 7, 1948, gross haematuria; Nov. 9., Addis count 2,000,000 R.B.C. in 12 hours; Nov. 23, Addis count 10,000,000 R.B.C. in 12 hours; Dec. 26, occasional R.B.C.; trace of albumen: Dec. 29, gross haematuria; April 4, 1949, trace of albumen; occasional R.B.C. A further Addis count was not performed.

Blood counts on Oct. 7, 1948, Hb. $7^{\circ}{ }_{\mathrm{o}}$ (Sahli) : W.B.C., 13,000. Platelets abundant. Bleeding and clotting times normal.

Mantoux test on Oct. 7, 1948, 1 10,000 negative.

Jones and Moore (1946) have reviewed the association of purpura with rheumatic fever and acute nephritis. While admitting that cutaneous erythemas of the $E$. multiforme type may occur in rheumatic fever, they consider true purpura uncommon, probably occurring in less than $1 \%$ of cases. They quote Fishberg to show that purpura is equally rare in nephritis. The common relapse of abdominal pain and haematuria in this child suggests a common aetiology, and it is likely that the original purpura belonged to the same syndrome. No other evidence is available to make a distinction from acute nephritis, and without the jejunitis no doubts would have been raised. The association of enteritis with nephritis has usually been in the chronic state and is widely reported under the title ' uraemic enteritis.' The child was certainly not uraemic, and it is debatable whether some cases of uraemic enteritis are not, in fact, vascular in origin.

A definite diagnosis would depend on an accurate distinction between acute nephritis and anaphylactoid purpura. Gairdner (1948) produces evidence to show that the distinction is largely artificial, although the extremes present characteristic pictures.

Case 4. E.W., a girl, aged 10 years, was admitted on October 8, 1948. Eight days before admission to hospital, she complained of epigastric pain and vomited several times. On one cocasion, the vomit was bloodstained. The pain and vomiting persisted for three days and then subsided, to return two days before admission. On the night before she was admitted she vomited some bright red blood. Three days before admission she had complained of stiffness and pain in both knees, and the mother thought that they had been slightly swollen. A short time before this illness began there had been a transient, painless swelling of the right ankle. There was no history of recent infection.

Condrion on Admission. The child was flushed and tired, with a temperature of $99 \cdot 2^{*} \mathrm{~F}$. The tonsils were red and large, with a yellow exudate. There was an angular stomatitis and a generalized rash, having the appearance of small papules. There was no evidence of joint swelling.

Progress. Penicillin, 50,000 units six-hourly, was given and the child appeared to improve. The rash quickly faded. Three days later, the temperature was normal and the throat healthy, but the child was restless and vomited several times. There was no complaint of abdominal pain. On October 14, 1948, a fresh rash appeared, consisting of purpuric spots over the buttocks and thighs, having the characteristics of the HenochSchönlein exanthem. Four days later she complained of colicky abdominal pain and was constipated. She was drowsy and her appetite poor. On October 21 a profuse purpuric rash appeared. She complained of severe abdominal pain and vomited several times. The abdomen was distended and slightly tender on the right side. After a time this subsided, and the next day the stools were loose, but not blood-stained.

The abdomen became distended during the next two days. A radiograph showed numerous fluid levels suggesting intestinal obstruction. She continued, however, to have frequent offensive stools. After three days the pain ceased, but the stools were not normal until October 30. No distension of the abdomen was then noticed. 
On November 4 a barium meal showed no abnormality, and a fortnight later she was eating well, gaining weight, and free from purpura.

Tonsillectomy was later considered advisable, and to cover the operation on December 6 procaine penicillin, $1 \mathrm{ml}$. daily, was given. The urine again became smoky after the operation, but a week later there was only a trace of albumen and an occasional red cell.

She was discharged home on February 4, 1949, when the urine was clear, but the B.S.R. was still $30 \mathrm{~mm}$. in 1 hour (micro-method).

LABORATORY INVESTIGATIONS. Urine analysis on Oct. 8, 1948, showed numerous R.B.C.s and heavy precipitate of albumen. Similar results were observed on Oct. 12 and Nov. 1. On Dec. 6 there was gross haematuria. On Feb. 4, 1949 there was no albumen, nor R.B.C.s. An Addis count was not performed.

Blood count on Oct. 8, 1948. Hb. 80\% (Sahli) ; W.B.C. 12,000. Hess test negative. On Oct. 12, bleeding time was $2 \frac{1}{2}$ mins.; clotting time 4 mins.; platelets abundant.

A chest radiograph on Oct. 8, 1948, showed enlarged left hilar glands and infiltration at the left apex. A Mantoux test on the same day was positive $1 / 1,000$.

A throat swab on Oct. 10, 1948, showed a slight growth of haemolytic streptococci.

The abdominal symptoms are of interest here in that radiographs showed a picture highly suggestive of paralytic ileus at a time when diarrhoea was still present. Brynjulfsen (1948) has reported this paradox in his cases of acute jejunitis and it may well be related to a widespread disturbance of normal peristalsis.

It will be noted that she was probably passing through her primary tuberculous infection at this time (cf. Case 2) and that although there was tonsillar sepsis on admission, few haemolytic streptococci were grown.

Case 5. D.M., a boy aged $8 \frac{1}{2}$ years, had previously been admitted to a medical ward and diagnosed as anaphylactoid purpura. That attack was complicated by severe abdominal pain with melaena, but he recovered after several weeks and was discharged home. Six months later, although he had recently been well, he had sudden acute mid-abdominal pain. This became colicky, and he vomited several times and quickly looked ill. He passed several blood-stained motions, but for a few hours before admission the bowels had not moved. Examination showed an ill child with a purpuric rash on the legs characteristic of anaphylactoid purpura. A large tumour was palpable in the left iliac fossa and the diagnosis of intussusception was made.

OPERATION FINDINGS. There was some clear fluid in the peritoneal cavity and a colic intussusception was discovered. The bowel was not unduly haemorrhagic and no explanation could be found for the profuse melaena. Operation was successful and the postoperative course was uneventful. No further purpura occurred and there was no haematuria.

\section{Discussion}

The intestinal lesion in Cases 1, 2, and 3 were essentially similar. In each, the segment of bowel affected was sharply separated from normal tissue, The mesentery and bowel were oedematous and of a curiously intense scarlet colour. There was no suggestion of such discoloration of the blood as might have been expected had there been interstitial bleeding. Despite the resemblance to an acute inflammatory erythema, the process did not spread to adjacent coils of gut. On each occasion a descriptive diagnosis of acute regional enteritis was made and only the later developments raised doubt as to the true diagnosis. In Case $\mathbf{4}$ a similar, though less severe, clinical course was accompanied by evidence of disordered peristalsis. In Case 5 this peristaltic disturbance seems to have induced true intussusception.

These five cases did not appear explicable in terms of mucosal purpura. The absence of any pigmentation of the tissues, together with doubts about the existence of any haemorrhagic tendency in this disease, further suggested that localized bleeding into the gut wall was not of primary importance. Nevertheless, the common recurrence of purpura and intestinal symptoms strongly suggests that the same vascular lesion is operative.

The Vascular Lesion. The rash normally consists of blood-stained macules, though simple oedema may occur. Occasional lesions become gangrenous resembling those seen in purpura necrotica (Sheldon, 1947). In either case, their local distribution may be occasioned by trivial injury. Histological changes are restricted to the small vessels of the corium which are surrounded by a cuff of white cells (Gairdner, 1948). Tissue eosinophilia is sufficiently frequent to suggest a local anaphylactic reaction. There is some swelling of the collagen fibres, but no fragmentation and there are no areas of fibrinoid degeneration. Capillary microscopy during the appearance of the rash shows that the exudate comes from the end of the pre-capillary arteriole and that the capillary wall remains intact (Humble, 1949). Capillary fragility tests have been equivocal. Davis (1948) found $25 \%$ positive in his series, but gives insufficient data for a proper appraisal of his results. Limited personal experience with a direct suction method has shown a marked difference between the capillaries of the purpuric areas and the surrounding skin which persists until the rash is barely visible. For this reason the true resistance is difficult to estimate and low readings may be obtained because sufficient care is not taken to map the distribution of the fading lesions.

The renal lesion has been taken to indicate a degree of capillary damage. It is chiefly remarkable among the complications of this disease in that it may progress to a chronic stage indistinguishable throughout its course from Type I nephritis (Ellis, 
.1949). Any process, however, which leads to persistent glomerular haemorrhage might be expected to proceed to crescent formation and later capsular fibrosis. Indeed, it has recently been suggested that pre-capillary vasospasm is the immediate cause of glomerular haemorrhage in acute nephritis (Ellis, 1949).

Although abdominal symptoms are seen in over $50 \%$ of cases admitted to paediatric units, pathological details are lacking. The colic, when severe, may suggest intussusception and operation has usually been advised to eliminate this possibility. Several authors have described the appearance of the bowel (Bailey, 1930; - Mailer, 1938; Barnes and Duncan, 1941) and all have agreed that haemorrhagic extravasation into the intestinal wall is present. Bailey (1930) states that the appearance might be reproduced by the injection of fresh blood under the serosal surface and so emphasizes the absence of tissue-staining by bile pigments.

The lower ileum is usually involved (Gairdner, 1948) though both stomach and jejunum may be affected (Bailey, 1930; Silbermann, 1890). Local ulceration of the mucosa associated with fibrinoid necrosis of the small vessels has been reported (Wassilieff, 1937), but most accounts merely reveal localized sub-mucosal haemorrhage, even though previous operation had shown acute engorgement (Sturtevant and Graef, 1933).

Anaphylactoid purpura may be described as a diffuse arteriolitis, but it is impossible to explain the abdominal lesion simply in terms of damage to the arterioles. Such damage has only been noted in the submucosa, the larger vessels appearing normal. On the analogy of the intestinal lesions found in malignant hypertension and in periarteritis nodosa which remain localized although the underlying vascular change is widespread, it is suggested that vasospasm is a complication of the initial vascular damage. It is significant that a similar form of regional enteritis may complicate symmetrical cortical necrosis of the kidney (Dunn and Montgomery, 1941), in which primary vasospasm is generally accepted as the cause of the renal lesion, and Campbell and Henderson (1949) have shown that both renal and intestinal lesions may occur simultaneously.

The appearance at operation of acute regional enteritis is not, however, entirely explicable by local vasospasm. The bright red hyperaemic tissue indicates a fast blood-flow through dilated vessels, whereas in paralytic distension following spasm it might be expected that the blood-flow would be sluggish and that there would be extravasation of blood into the tissues. The intestinal lesion could best be explained by a submucosal shunt with intense local spasm diverting the greater part of the blood-flow to the outer layers of the bowel. A mechanism of this type has recently been demonstrated by Barclay and Bentley (1949) in the gastric mucosa, and it is at least possible that similar shunts may occur throughout the bowel. Such a mechanism provides an acceptable explanation of the intensity and transience of the symptoms. Irreparable damage would then depend on the degree of mucosal ischaemia and the consequent infection. Vascular disorders at the submucosal level may be expected to disturb the normal integration of the intrinsic nerve plexuses. It is probable that the abnormal peristalsis in Case 4 and the development of true intussusception in Case 5 are symptomatic of this disturbance.

Despite the generally accepted view that anaphylactoid reactions primarily affect capillary endothelium, it may be that in anaphylactoid purpura any capillary damage which occurs is conditioned by pre-capillary vasospasm and consequent anoxia.

\section{Summary}

The alimentary lesion in anaphylactoid purpura is described and five illustrative cases are reported in detail.

It is suggested that in anaphylactoid purpura local vasospasm is responsible for the segmented lesions in the bowel, such vasospasm being secondary to damage of the arterioles.

I am pleased to acknowledge my gratitude to Professor R. W. B. Ellis, Drs. D. Nicholson and J. L. Henderson, and to Mr. J. J. Mason Brown, Miss R. M. Mackay, and Mr. F. H. Robarts for permission to report cases originally admitted under their care. The photographs were kindly provided by Mr. F. H. Robarts. Finally I am grateful to Professor R. W. B. Ellis for his continued advice and encouragement.

\section{REFERENCES}

Bailey, H. (1930). Brit. J. Surg., 18, 234.

Barclay, A. E., and Bentley, F. H. (1949). Brit. J. Radiol., 22, 62.

Barnes, C. G., and Duncan, G. W. (1941). Brit. J. Surg., $29,253$.

Brynjulfsen, B. C. (1948). Acta chir. scand., 96, 361.

Campbell, A. C. P., and Henderson, J.' L. (1949). Archives of Disease in Childhood, 24, 269.

Croft, P. B., and Peters. R. A. (1945). Lancet, 1, 266.

Davis, E. (1948). Blood, 3, 129.

Dunn, J. S., and Montgomery, G. L. (1941). J. Path. Bact., 52, 1.

Ellis, A. W. M. (1949). Arch. intern. Med., 84, 159.

Gairdner, D. (1948). Quart. J. Med., 17, 95.

Henoch, E. (1874). Berl. klin. Wschr., 11, 641.

Humble, J. G. (1949). Blood, 4, 69.

Jones, R. H., and Moore, W. W. (1946). Amer. Heart J., 32, 529. 
Mailer, R. (1938). Brit. J. Surg., 25, 517.

Osler, W. (1914). Brit. med. J., 1, 517.

Parrot, J. L. (1942). C. R. Soc. Biol., Paris, 136, 715.

Schönlein, J. L. (1837). 'Allgemeine und spezielle Pathologie und Therapie,' vol. 2, p. 48 . Freyburg.

Sheldon, J. H. (1947). Archives of Disease in Childhood, 22, 7 .
Silbermann, O. (1890). In 'Paediatrische Arbeiten,' ed. Baginsky, A., p. 237. Berlin.

Sturtevant, M., and Graef, I. (1933). Med. Clin. N. Amer., 17, 91.

Vaughan, J., Thomson, M., and Dyson, M. (1946). J. Path. Bact., 58, 749.

Wassilieff, P. (1937). Nord. med. Tidskr., 14, 1322.

Willan, R. (1808). ' 'On Cutaneous Diseases.' London. 